\title{
A new procedure combining local resection with endoscopic submucosal dissection for low rectal tumor: a four-case series $\square$
}

\section{다)(i) $\odot=$}

\author{
Authors \\ Mukai $^{1}$ \\ Institutions \\ 1 Department of Gastroenterology, Hiroshima City Asa \\ Citizens Hospital, Hiroshima, Japan \\ 2 Department of Surgery, Hiroshima City Asa Citizens \\ Hospital, Hiroshima, Japan \\ submitted 26.3.2019 \\ accepted after revision 5.8.2019

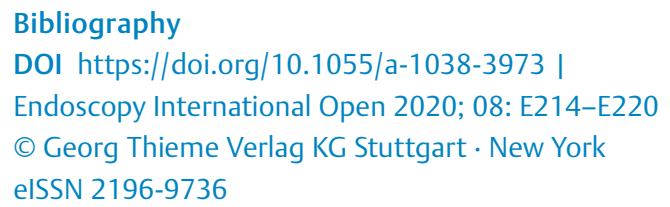

Naoki Asayama ${ }^{1}$, Shinji Nagata' ${ }^{1}$, Masashi Miguchi ${ }^{2}$, Kenjiro Shigita ${ }^{1}$, Taiki Aoyama ${ }^{1}$, Akira Fukumoto ${ }^{1}$, Shinichi

\section{ABSTRACT}

Rectal tumors are traditionally resected by proctectomy to ensure the achievement of negative margins, an approach associated with an adverse impact on subsequent quality of life due to sequelae such as permanent stoma and urinary and sexual dysfunction. Many studies have now demonstrated that recurrence after local excision of early rectal tumors is significantly higher than would typically be expected. We have developed a new procedure, described herein, that combines local resection with endoscopic submucosal dissection for low rectal tumor. We report four consecutive cases (three submucosal tumors and one tumor with clinical deep submucosal invasion) treated at Hiroshima City Asa Citizens Hospital between January 2009 and March 2018. The mean duration of the procedure was 137 minutes. The en bloc resection and histologically complete resection rates were $100 \%$. Delayed bleeding and perforation rates were $0 \%$. Postoperative complications were fever and anal pain (one case each). All patients recovered with conservative therapy. No recurrence was found in any of the four patients during a follow-up period of 56 months. Our combined endoscopic and surgical procedure for low rectal tumors enabled definite negative vertical margins, reduced tumor volume, allowed for accurate pathological diagnosis, preserved rectal function, and aided the decision on additional therapy.

\section{Introduction}

Rectal tumors are traditionally resected by proctectomy to ensure negative margins. However, major rectal surgery by proctectomy often results in permanent stoma with a significant negative impact on patient-reported outcomes. In addition, postoperative complications, such as disturbed defecation, genitourinary dysfunction, or anastomotic dehiscence, may develop following rectal surgery [1,2]. Local excision, including transanal excision (TAE) and transanal endoscopic microsurgery (TEM), is preferable because it is associated with low morbidity, quick recovery, and minimal effect on long-term bowel function. However, local excision by the transanal approach is difficult because of the limited operative view and difficulty in determining the appropriate resection line. Furthermore, many studies have now demonstrated that the incidence of recurrence after local excision of early lesions is significantly higher than would typically be expected.

Endoscopic submucosal dissection (ESD) has a therapeutic advantage over conventional endoscopic mucosal resection (EMR) for colorectal tumors and enables a higher en bloc resection rate to be achieved, resulting in enhanced curability and more accurate histopathological assessment [3-8]. The clinical advantages of rectal ESD include the ability to avoid invasive surgery and stoma creation, and ensure functional prognosis. However, ESD for colorectal tumors is more technically challen- 


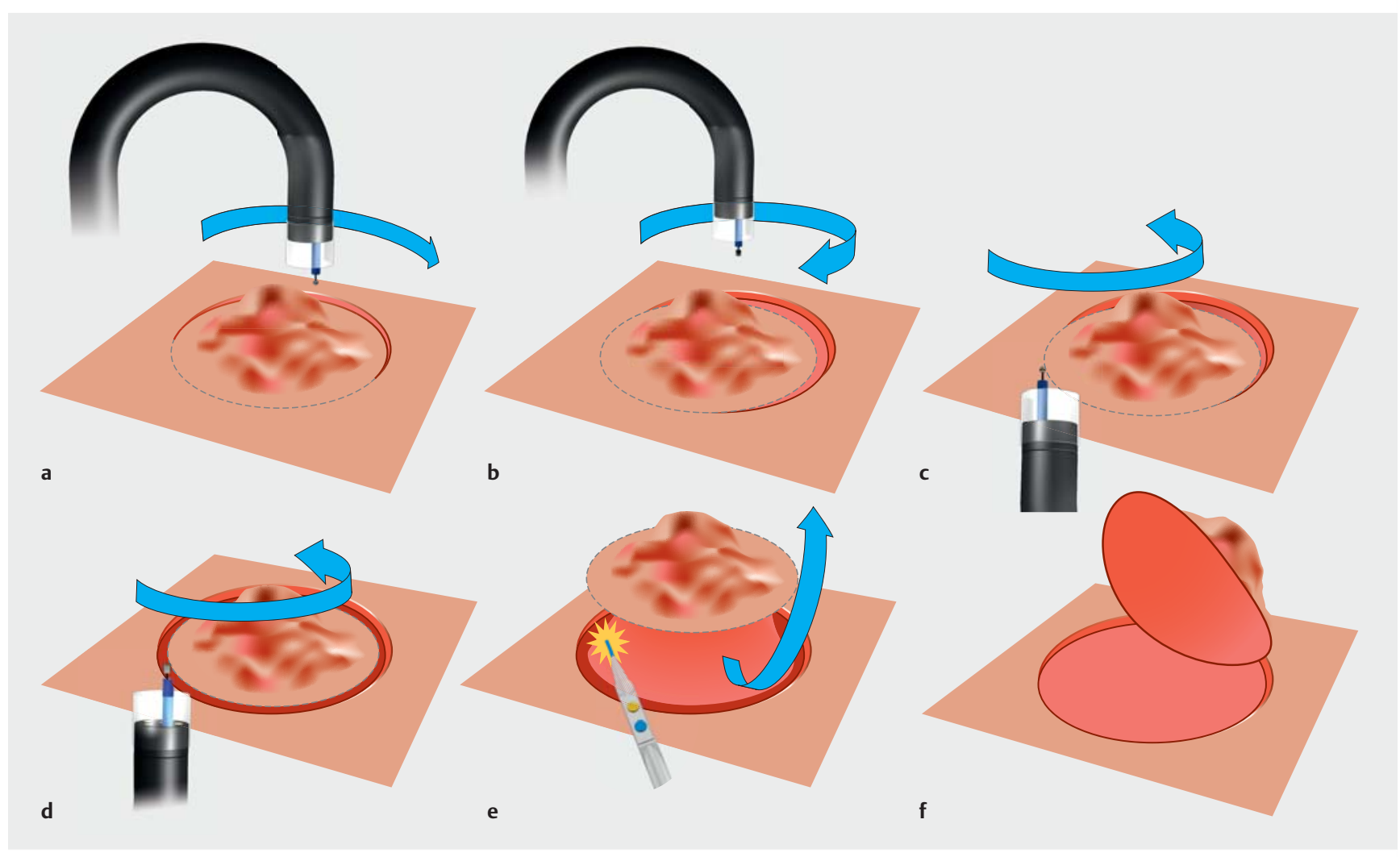

- Fig. 1 Schema showing the combined surgical procedure. a Using the DualKnife, a hemicircumferential incision was made in the mucosa around the lesion on the oral side. $\mathbf{b}$ Oral-side dissection was performed first with an ITknife nano with a retroflexed view. c, $\mathbf{d}$ An anal-side circumferential incision was made with the DualKnife. The tissue was then dissected along the submucosal layer with the ITknife nano. The dissection was continued just above the muscle layer, and the dissection was stopped at the point where the muscle layer was retracted toward the tumor. e, $\mathbf{f}$ Local excision was then performed underneath the tumor with the transanal approach. The muscle layer was resected, if needed.

ging and requires considerable experience compared with EMR; the risk of adverse events such as perforation is also greater [4]. These complications possibly occur during dissection of the muscle layer, suggesting that ESD is suitable for resection in the mucosal and submucosal layers, but not muscle. Submucosal tumor (SMT) and tumor with deep submucosal invasion can result in failure to achieve en bloc resection by colorectal ESD alone [5].

We have developed a new procedure, described herein, that combines local resection with the ESD technique for low rectal tumor.

\section{Case series}

A total of four consecutive patients (one man, three women) underwent endoscopic and surgical treatment for low rectal tumor at Hiroshima City Asa Citizens Hospital between January 2009 and March 2018. This method is indicated when endoscopic ultrasonography (EUS) reveals that the tumor is limited to the submucosa. No combined surgery was performed for upper rectal tumors, because it is very difficult to perform local excision in upper rectal tumors. However, more TAE than ESD procedures have been performed for low rectal tumors because surgeons can easily reach tumors via a transanal approach, as is the case with hemorrhoid surgery.

The combined surgery was composed of an endoscopic part and a surgical part ( $\triangleright$ Fig. 1). In the endoscopic part, the patients were placed under general anesthesia. Then a hemicircumferential incision of the oral side was made in the mucosa around the lesion with the DualKnife (Olympus, Tokyo, Japan). The first dissection was on the oral side and was performed using an ITknife nano (Olympus) with a retroflexed view. Next, a hemicircumferential incision was made on the anal side with the DualKnife (Olympus). Then, the tissue was dissected along the submucosal (SM) layer with the ITknife nano. We continued the dissection just above the muscle layer, and stopped the dissection at the point where the muscle layer was retracted toward the tumor ( $\vee$ Video 1 ). In the initial case, we used only the DualKnife for incision and dissection because the ITknife nano had not yet been introduced into practice.

The surgical part followed the endoscopic part, and for this, the patient was then placed in the jackknife position. At this point, the tumor was visible through the anus by dilating the anus with the use of an anal retractor. Local excision was then performed underneath the tumor with the transanal approach. The muscle layer was resected, if needed. The tumor could then be extracted through the anal canal. Finally, the suture lines 
Table 1 Patient demographics and clinical characteristics of the four patients.

\begin{tabular}{|c|c|c|c|c|c|c|c|c|}
\hline $\begin{array}{l}\text { Pa- } \\
\text { tient }\end{array}$ & $\begin{array}{l}\text { Age, } \\
\text { years| } \\
\text { sex }\end{array}$ & $\begin{array}{l}\text { Tumor } \\
\text { location }\end{array}$ & $\begin{array}{l}\text { Tumor } \\
\text { diame- } \\
\text { ter, mm }\end{array}$ & $\begin{array}{l}\text { Clinical } \\
\text { manifes- } \\
\text { tation }\end{array}$ & $\begin{array}{l}\text { Invasion } \\
\text { depth by } \\
\text { EUS }\end{array}$ & Preoperative biopsy & Stage & Final diagnosis \\
\hline 1 & $60 /$ Male & $\begin{array}{l}\text { Cecum/ } \\
\mathrm{Rb}\end{array}$ & 50 & $\begin{array}{l}\text { Hemato- } \\
\text { chezia }\end{array}$ & SM & No malignancy & $\begin{array}{l}\text { Stage I (Lugano } \\
\text { classification) }\end{array}$ & MALT \\
\hline 2 & $\begin{array}{l}64 / \mathrm{Fe}- \\
\text { male }\end{array}$ & $\mathrm{Rb}$ & 30 & $\begin{array}{l}\text { Hemato- } \\
\text { chezia }\end{array}$ & SM & $\begin{array}{l}\text { MALT with focal DLBCL } \\
\text { transformation }\end{array}$ & $\begin{array}{l}\text { Stage I (Lugano } \\
\text { classification) }\end{array}$ & MALT \\
\hline 3 & 58/Male & $\mathrm{Rb}$ & 40 & $\begin{array}{l}\text { Hemato- } \\
\text { chezia }\end{array}$ & SM & Suggested MALT & $\begin{array}{l}\text { Stage I (Lugano } \\
\text { classification) }\end{array}$ & $\begin{array}{l}\text { MALT with focal DLBCL } \\
\text { transformation }\end{array}$ \\
\hline 4 & $\begin{array}{l}83 / \mathrm{Fe}- \\
\text { male }\end{array}$ & $\mathrm{Rb}$ & 20 & $\begin{array}{l}\text { None } \\
(\text { FOBT }+)\end{array}$ & SM-MP & $\begin{array}{l}\text { Adenocarcinoma } \\
\text { (tub1 >tub2) }\end{array}$ & $\begin{array}{l}\text { Stage I (TMN } \\
\text { classification) }\end{array}$ & $\begin{array}{l}\text { Adenocarcinoma } \\
\text { (tub1 > tub2), pT2 }\end{array}$ \\
\hline
\end{tabular}

Rb, rectum below peritoneal reflection (=low rectal); SM, submucosal; MP, muscularis propria; MALT, mucosa-associated lymphoid tissue; DLBCL, diffuse large B-cell lymphoma; FOBT, fecal occult blood test.

were examined endoscopically for bleeding, stenosis, and leakage, and then we sutured the defect in the major axis of the intestine perpendicularly to prevent intestinal stenosis.

We used a single endoscope GIFH260Z (Olympus) with a transparent hood attached to the tip with carbon dioxide insufflation. We usually used a standard tip hood. Hyaluronic acidindigo carmine mixed with glycerol was then injected into the SM layer using a 21-gauge needle. A 1:1 mixture of $0.4 \%$ sodium hyaluronate (Muco Up; Johnson \& Johnson, New Brunswick, New Jersey, United States) and $10 \%$ glycerin solution was prepared to which was added a small amount of indigo carmine (indigo carmine/Muco Up+glycerin: $0.2 \mathrm{~mL} / 20 \mathrm{~mL}$ ). The electrosurgical unit was set to Dry Cut mode (Effect 2, $30 \mathrm{~W}, \mathrm{VIO}$ 300; Erbe Elektromedizin GmbH, Tübingen, Germany) for making incisions and to Swift coagulation mode (Effect 2, $30 \mathrm{~W}$, VIO 300) for cutting.

Patient demographics and clinical characteristics are summarized in $>$ Table 1. The main clinical manifestation was hematochezia in three patients, and the fecal occult blood test was positive in one patient.

The mean age \pm SD of patients enrolled was $66 \pm 9.9$ years (range 58-83). Mean lesion size was $36 \pm 9.6 \mathrm{~mm}$ (range 25$50 \mathrm{~mm}$ ). Three of four cases were reddish-elastic hard SMTs ( $\vee$ Fig.2). Magnification endoscopy with narrow-band imaging revealed findings similar to the tree-like appearance of abnormal microvessels in the thin layer of mucosa. Furthermore, EUS showed that the tumor was an internally heterogeneous lowechoic mass and was limited to the submucosa.

Biopsy was subsequently performed in three SMT cases. In one case, there were no malignant findings on biopsy, and the remaining two cases were diagnosed as mucosa-associated lymphoid tissue lymphoma (MALToma).

The diagnosis of MALToma was established by combined surgery in three cases; however, two of these three cases were confirmed to have undergone partial transformation to diffuse large-cell B-cell lymphoma (DLBCL).

One of four cases was a sessile lesion measuring $25 \mathrm{~mm}$ ( $\triangleright$ Fig. 3, $\triangleright$ Fig. 4). We diagnosed this tumor as clinical (c) T1b carcinoma (submucosal invasion depth $\geq 1000 \mu \mathrm{m}$ ) on magnify- ing colonoscopy and EUS. We recommended surgical intervention, but the patient strongly desired anal preservation and declined surgery because she had previously undergone radical colectomy twice for advanced colorectal carcinoma 15 years and 20 years earlier, respectively. Contrast-enhanced computed tomography showed no lymph node (LN) or distant metastasis. The line of demarcation between the mass and the muscularis propria was seen to be preserved on magnetic resonance imaging. Combined surgery was performed based on a

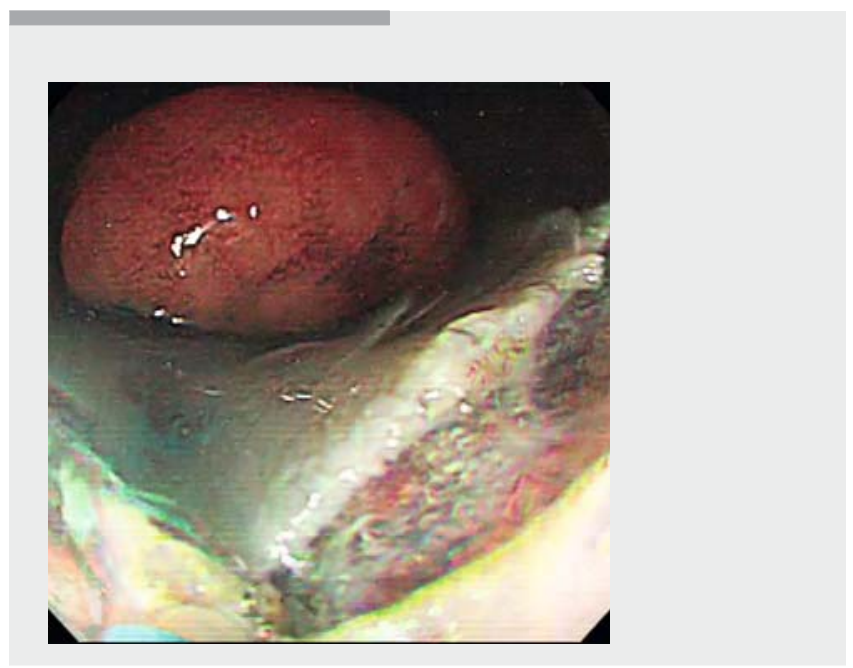

Video 1 Details of the combined endoscopic and surgical procedure for rectal tumor performed in case 2. Under general anesthesia, a hemicircumferential incision of the oral side was made in the mucosa around the lesion using a DualKnife. The first dissection was on the oral side and was performed using an ITknife nano with a retroflexed view. Next, a hemicircumferential incision was made on the anal side with the DualKnife. Then, the tissue was dissected along the submucosal layer with the ITknife nano. The endoscopist continued the dissection just above the muscle layer, and stopped the dissection at the point where the muscle layer was retracted toward the tumor. After the endoscopic dissection was completed, the patient was placed in the jackknife position and the surgeons then continued the procedure. 

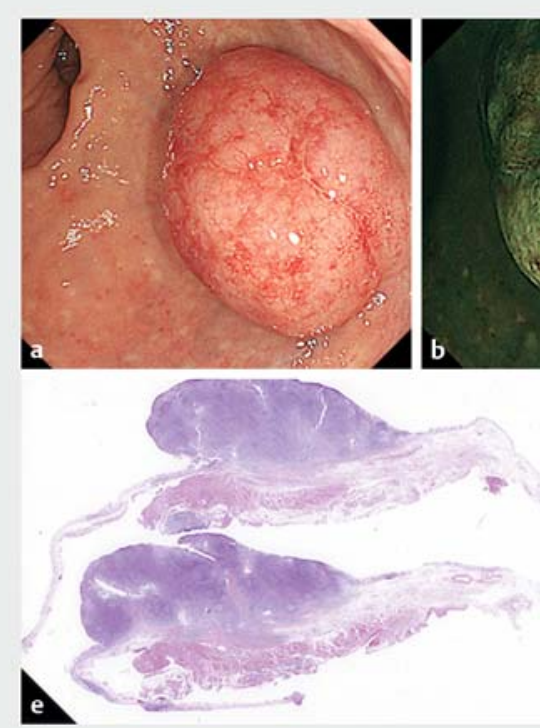
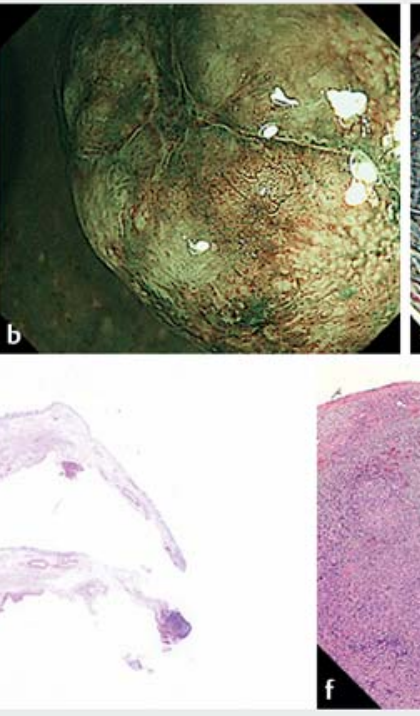
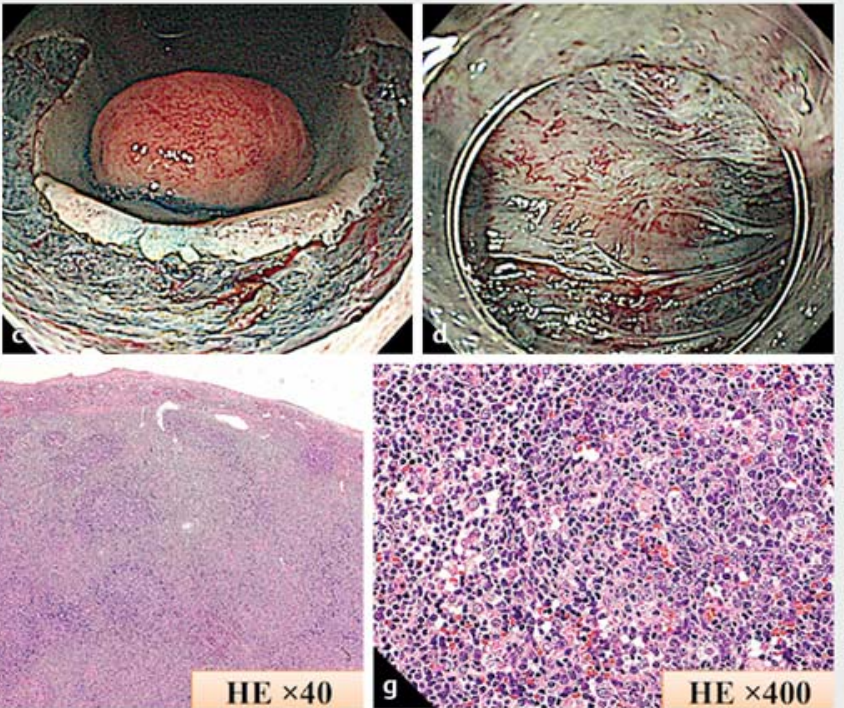

- Fig. 2 Case 2. a Colonoscopy shows a reddish-elastic hard submucosal tumor. b Magnification endoscopy with narrow-band imaging revealed findings similar to the tree-like appearance of abnormal microvessels on the thin layer of mucosa. c Oral-side dissection was performed first with an ITknife nano with a retroflexed view. $\mathbf{d}$ We continued the dissection just above the muscle layer, and stopped the dissection at the point where the muscle layer was retracted toward the tumor. e Resected specimen showing a $30 \mathrm{~mm}$ tumor. $\mathbf{f}, \mathbf{g}$ Pathological findings in the resected specimen showing diffuse atypical lymphocytes with centrocyte-like cells in the mucosa and submucosal layer. Immunohistochemical staining findings were compatible with a diagnosis of mucosa-associated lymphoid tissue (MALT) lymphoma with focal diffuse large-cell B-cell lymphoma (DLBCL) transformation.
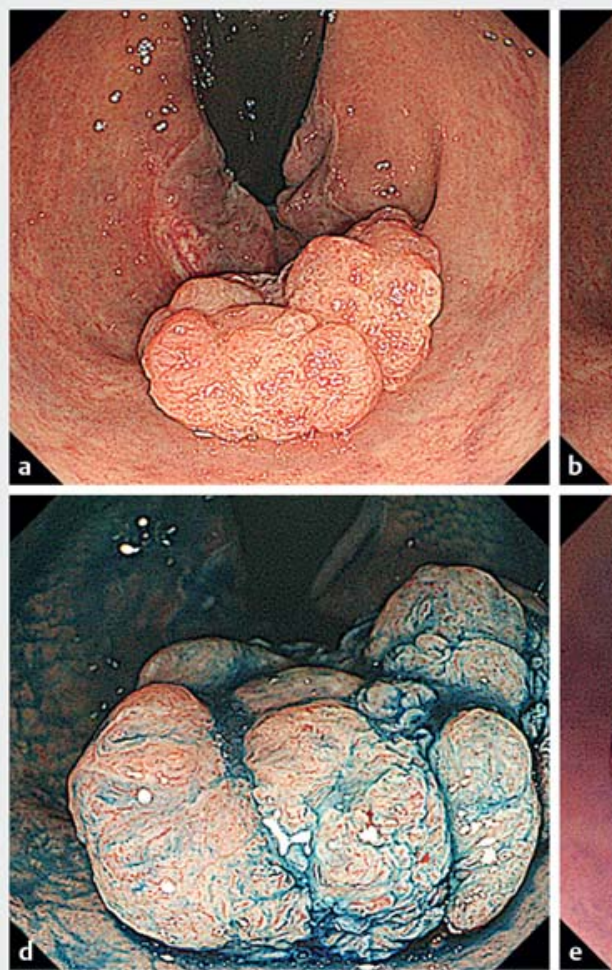
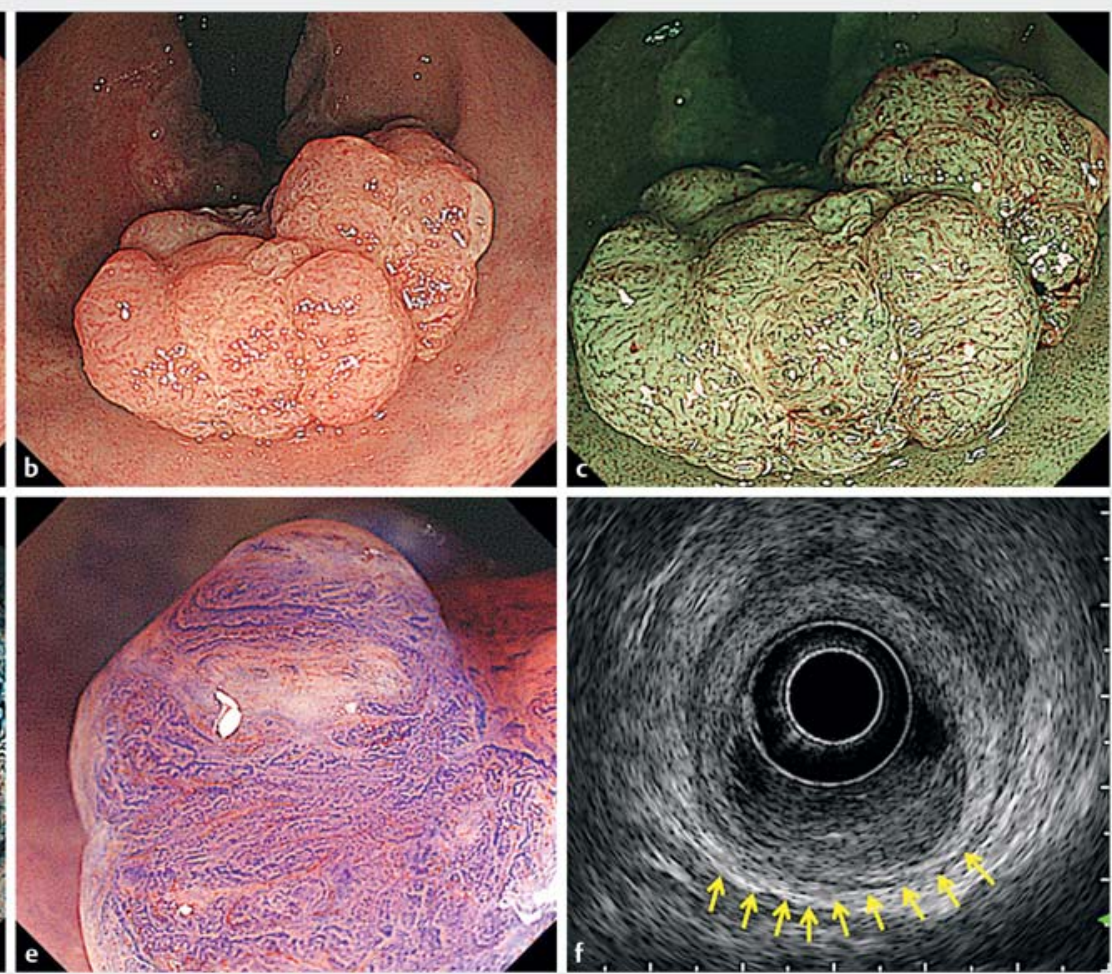

- Fig. 3 Case 4. a, b Colonoscopy showing a sessile lesion measuring $25 \mathrm{~mm}$ in the lower rectum. c Narrow-band imaging magnifying endoscopy showed that the vessel pattern had a variable caliber and irregular distribution and the surface pattern was obscure. $\mathbf{d}$ Indigo Carmine dye spraying showed the tumor and its margins more clearly, and a macroscopic type 0 -Is carcinoma was identified. e Magnifying colonoscopic view with Crystal Violet staining revealed a type VI highly irregular pit pattern and partial VN pit pattern. $f$ We diagnosed this tumor as clinical T1b carcinoma on magnifying colonoscopy and EUS. 

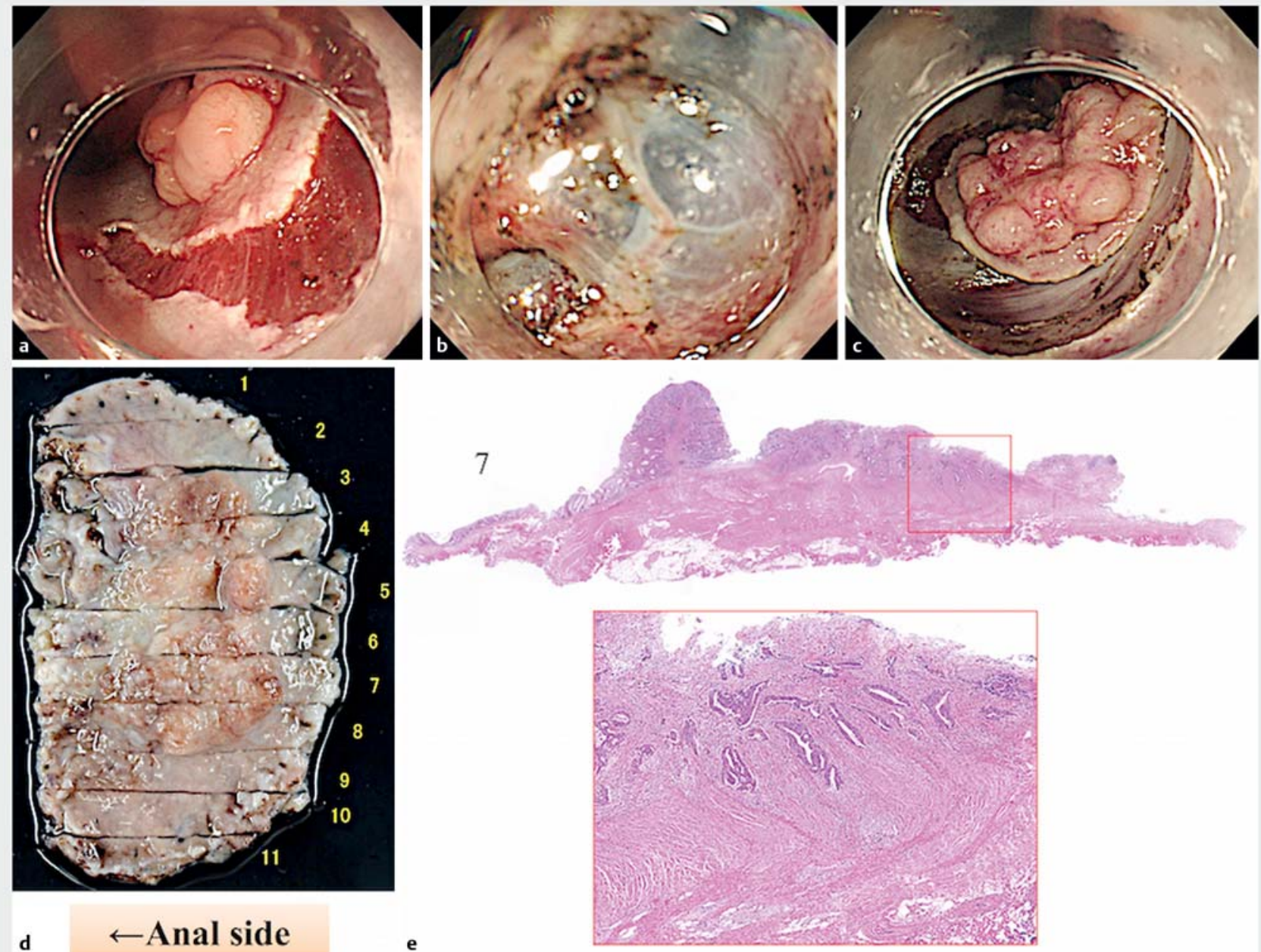

- Fig. 4 Case 4. a-c Details of the combined surgical procedure performed in case 4. $\mathbf{d}$ Resected specimen showing a $20 \mathrm{~mm}$ tumor and the numbered segments. e Pathological findings in the resected specimen (segment no. 7). Tumor cells had infiltrated into the muscle layer.

- Table 2 Clinical outcomes for the four patients.

\begin{tabular}{|c|c|c|c|c|c|c|c|c|c|c|}
\hline $\begin{array}{l}\mathrm{Pa}- \\
\text { tient }\end{array}$ & ASA & $\begin{array}{l}\text { Deepest } \\
\text { level of } \\
\text { resec- } \\
\text { tion }\end{array}$ & $\begin{array}{l}\text { Operation } \\
\text { time, min }\end{array}$ & $\begin{array}{l}\text { Blood } \\
\text { loss, } \\
\mathrm{mL}\end{array}$ & $\begin{array}{l}\text { Major } \\
\text { complica- } \\
\text { tions }\end{array}$ & $\begin{array}{l}\text { Hospi- } \\
\text { tal } \\
\text { stay, } \\
\text { days }\end{array}$ & Margins & $\begin{array}{l}\text { Adjuvant } \\
\text { therapy }\end{array}$ & $\begin{array}{l}\text { Re- } \\
\text { sponse } \\
\text { to treat- } \\
\text { ment }\end{array}$ & $\begin{array}{l}\text { Follow-up } \\
\text { after treat- } \\
\text { ment, } \\
\text { months }\end{array}$ \\
\hline 1 & 1 & MP & 137 & 100 & $\begin{array}{l}\text { Fever, dis- } \\
\text { tension }\end{array}$ & 10 & Free & $\begin{array}{l}\text { Operation che- } \\
\text { motherapy }\end{array}$ & $C R$ & 125 \\
\hline 2 & 2 & MP & 132 & 0 & Anal pain & 8 & Free & Radiotherapy & $C R$ & 48 \\
\hline 3 & 2 & MP & 151 & 50 & Anal pain & 10 & Free & Chemotherapy & $C R$ & 34 \\
\hline 4 & 2 & MP & 127 & 0 & None & 8 & Free & None & & 15 \\
\hline
\end{tabular}

ASA, American Society of Anesthesiologists score; CR, complete response; MP, muscularis propria.

diagnosis of cT1N0M0, and was considered to be curative. Because the final diagnosis was tub2 >tub1, pT2, INF b, ly1, v1, budding $\mathrm{G} 1$, cN0, cM0, we recommended proctectomy with regional LN dissection. However, the patient declined further treatment.
Outcomes related to combined surgery are shown in $>$ Table 2. The mean duration of the procedure was $137 \pm 9$ minutes (range, 127-151). The en bloc resection and histologically complete resection rates were $100 \%$. Postoperative complications were fever and anal pain (one case each). There were no 
cases with bleeding that required transfusion. All patients recovered under conservative therapy. The mean duration of hospitalization was $9 \pm 1$ days (range, $8-10$ ). No recurrence was found in any of these four patients during a follow-up period of 56 months. The three cases of MALToma who were given postoperative chemotherapy remain in complete remission (CR) and are currently being followed up.

\section{Discussion}

The greatest advantage of using the ESD technique before local excision is that it maintains an endoscopic view of the safety margin from the tumor, which cannot be achieved by local excision alone. The endoscopic retroflex view is especially useful for endoscopic diagnosis and treatment of rectal lesions spreading to the dentate line. Even when it is difficult to confirm an oral border by a transanal surgical approach, endoscopists can confirm an oral border directly with the retroflex view, and can accomplish mucosal incision via submucosal dissection. Using this ESD technique, surgeons can more reliably perform operations from the anal side when local excision is performed because the tumor margins can usually be identified by the surgeon under direct vision.

We continued the dissection just above the muscle layer, and stopped the dissection at the point where the muscle layer was retracted toward the tumor. This feature was presumably due to severe fibrosis with muscle layer retraction under the large nodular areas, which made distinguishing the submucosal layer from the muscle layer difficult. Furthermore, it was difficult to use proper countertraction, which made it even more difficult to complete the dissection. The advantage of this combined surgery is that it allows for resection up to the muscularis layer under direct vision. As a result, an adequate resection margin is completely secured by this combined procedure, and surgery from the anal side is also possible. This procedure enabled us to successfully resect all four tumors en bloc without damaging the tumor and with minimal operative time.

Mucosa-associated lymphoid tissue is predominantly found in the gastrointestinal tract and plays a vital role in immune surveillance, mucosal regeneration, and carcinogenesis. This type of lymphoma primarily occurs in the stomach and small intestine and rarely in the colon, accounting for less than $5 \%$ of cases $[9,10]$. Because the lymphoid tissue of the stomach is present in the mucosa, tumor cell infiltrates were mainly confined to the mucosa, forming elevated lesions. In contrast, the lymphoid tissue of the colon is located close to the muscularis mucosae, and so tumor cell infiltrates were mainly confined to the submucosa, forming a submucosal tumor $[9,10]$.

It has been reported that transformation to high grade DLBCL occurs at a frequency of approximately $10 \%$. Sufficient attention is necessary for transformation to DLBCL in MALToma $[9,10]$. Diagnosis by biopsy alone may be difficult, and biopsy may not always be feasible due to the increased vascularity seen in some lesions. EUS is indispensable for histological diagnosis of SMT; however, it is not necessarily easy to obtain samples for precise assessment of histopathological findings in fa- cilities where endoscopists are not familiar with EUS-guided fine needle aspiration.

In the absence of standardized treatment for colorectal MALToma, various methods have been used including surgical resection, chemotherapy, radiation, and endoscopic resection [9]. Previous studies reported that primary surgical treatment had a favorable influence on the prognosis of MALToma, especially for localized disease, and reported that the complete response (CR) rate, in particular for patients who received surgery-based treatments was the highest $[9,10]$. Our combined procedure allowed us to make an accurate confirmatory histological diagnosis, to achieve complete resection of the tumor, to achieve reduced tumor volume, and to decide the next treatment regimen. The indication for combined surgery for MALToma is limited to stage I disease (Lugano classification), which is a tumor located in the mucosa or submucosa with no lymphadenopathy.

We applied this procedure to colorectal carcinoma stage cT1b. The standard treatment for T1/T2 colorectal carcinoma is surgical resection including regional LNs. Operative invasiveness is maximal, and radical surgery is associated with an adverse impact on subsequent quality of life as its sequelae may include permanent stoma and genitourinary dysfunction. The value of local excision for curative treatment of early rectal carcinoma is debatable. The rates of postoperative complications and functional impairment are low, but the rates of local recurrence vary considerably depending on tumor characteristics, method of local excision, and length of follow-up. Additionally, prognosis after local excision is unfavorable. The local recurrence rate of $\mathrm{T} 1$ rectal carcinoma is reported to be about 0-20\% with local excision alone, and (chemo-)radiotherapy after local excision of $\mathrm{T} 1$ rectal carcinoma reduces the rate to around $0-8 \%$. The local recurrence of T2 rectal carcinoma is reported to be about $0-37 \%$ with local excision alone and is $0-$ $19 \%$ following a combination of local excision and (chemo-) radiotherapy. Local excision plus additional treatment seems to be effective for local control based on the previous literature $[1,2]$. Causes of local recurrence include undetected LN metastasis and consequent inadequate chemotherapy, incomplete resection of carcinoma, and implantation of tumor cells [2]. The high rate of local recurrence following local excision is probably due to poor visualization of the operative field; thus, the tumor margin could not be clearly observed. Visualization of the operative field during local excision was more difficult in the rectum because air or $\mathrm{CO}_{2}$ insufflation could not be used as in ESD. When the ESD technique was performed, the tumor margins were recognized clearly by high magnification chromocolonoscopy, which resulted in a lower recurrence rate. This combined procedure is considered to contribute to organ preservation and control of the resection margin.

TEM is reported to achieve a high $\mathrm{R} 0$ resection rate in a fullthickness fashion, and significantly reduces the need for further abdominal treatment or procedures. In contrast, TEM generally cannot be carried out when the distal tumor margin is within 3 $\mathrm{cm}$ of the anal verge or the tumor is large or protruding, given technical procedural difficulties. In contrast, rectal ESD has no limitations in regard to lesion size [3]. The clinical advantages 
of rectal ESD include the ability to avoid invasive surgery or a stoma, and to ensure functional prognosis. Furthermore, ESD for anorectal tumors close to the dentate line has been reported to be a safe and effective therapeutic method [6-8]; however, it seems that anorectal ESD, which is technically more difficult than colorectal ESD, should be performed by operators with ample experience in performing ESD [6-8]. Our combined surgery has the advantages of both local excision and ESD.

This report includes two different diseases that each has different standard treatment strategies. However, the common standard treatment for both diseases is surgical resection. We think that the application of this combined treatment to adenocarcinoma will be possible in the future, especially as Japan is an aging society and the number of elderly patients with concomitant disease will increase. Further experience is needed with this novel technique for management of rectal tumors in an effort to develop a low-morbidity diagnostic technique and a therapeutic modality option via surgical resection.

Our endoscopic and combined surgery for rectal tumors enabled us to achieve definite negative vertical margins, reduced tumor volume, provided an accurate pathological diagnosis, preserved rectal function, and can help the surgeon decide on additional treatment strategies.

Competing interests

None

\section{References}

[1] Jones HJS, Goodbrand S, Hompes R et al. Radiotherapy after local excision of rectal cancer may offer reduced local recurrence rates. Colorectal Dis 2019; 21: 451-459

[2] Junginger T, Goenner U, Hitzler M et al. Analysis of local recurrences after transanal endoscopic microsurgery for low risk rectal carcinoma. Int J Colorectal Dis 2017; 32: 265-271

[3] Kiriyama S, Saito Y, Matsuda T et al. Comparing endoscopic submucosal dissection with transanal resection for non-invasive rectal tumor: a retrospective study. J Gastroenterol Hepatol 2011; 26: 10281033

[4] Oka S, Tanaka S, Saito Y et al. Local recurrence after endoscopic resection for large colorectal neoplasia: a multicenter prospective study in Japan. Am J Gastroenterol 2015; 110: 697-707

[5] Asayama N, Oka S, Tanaka S et al. Endoscopic submucosal dissection as total excisional biopsy for clinical T1 colorectal carcinoma. Digestion 2015; 91: 64-69

[6] Imai K, Hotta K, Yamaguchi Y et al. Safety and efficacy of endoscopic submucosal dissection of rectal tumors extending to the dentate line. Endoscopy 2015; 47: 529-532

[7] Tamaru Y, Oka S, Tanaka S et al. Endoscopic submucosal dissection for anorectal tumor with hemorrhoids close to the dentate line: a multicenter study of Hiroshima GI Endoscopy Study Group. Surg Endosc 2016; 30: 4425-4431

[8] Matsumoto S, Mashima H. The efficacy of endoscopic submucosal dissection for colorectal tumors extending to the dentate line. Int J Colorectal Dis 2017; 32: 831-837

[9] Saito T, Toyoda H, Yamaguchi M et al. lleocolonic lymphomas: a series of 16 cases. Endoscopy 2005; 37: 466-469

[10] Kim S], Choi CW, Mun YC et al. Multicenter retrospective analysis of 581 patients with primary intestinal non-hodgkin lymphoma from the Consortium for Improving Survival of Lymphoma (CISL). BMC Cancer 2011; 11: 321 